\title{
A Study of the Esterases and Their Function in Candida lipolytica, Aspergillus niger and a Yeast-like Fungus
}

\author{
By G. I. LLOYD, E. O. MORRIS AND J. E. SMITH \\ Department of Applied Microbiology, University of Strathclyde, Glasgow C.I
}

(Accepted for publication 24 June 1970)

SUMMARY

Esterases, determined by polyacrylamide gel electrophoresis, were present when Candida lipolytica was grown in a liquid, shaken, glucose-mineral salts medium. Intracellular esterase activity increased during growth, but extracellular esterase activity was small and increased only marginally. Esterases were not detected in organisms grown on solid glucose-mineral salts medium, but were present when glycerol tributyrin replaced glucose.

At the onset of asexual sporulation in a yeast-like fungus, three new esterases occurred. Intracellular esterase activity increased, intracellular lipid utilization occurred, and the respiratory quotient decreased. No extracellular esterase activity was detected.

Esterases were only detected in Aspergillus niger at late stages of conidiation when intracellular lipid decreased. Esterase activity was not detected in the mitochondria or in the cell-free growth medium.

Esterases of all organisms tested hydrolysed glycerol tributyrin and were arbitrarily classified as lipases; intracellular lipid decreased with increase in esterase activity function. Esterase and profile changes may reflect a role of lipids in sporulation and physiological ageing.

\section{INTRODUCTION}

Gel electrophoresis has been shown by several workers to be a suitable technique for the study of esterases, and in some cases the esterase profile has been found to consist of a group of molecular species recognizable by their common enzymic activity on a 'general' ester substrate (Arnason \& Pantelouris, 1966; Robinson, 1966). The esterases comprise a family of enzymes exhibiting a very broad substrate specificity, and consequently a classification of esterases based on specificity is of little value. However, it is customary to distinguish lipases as a special class, defined by the International Union of Biochemistry (I96I) as a glycerol ester hydrolase, and it is recommended that glycerol ester emulsions should be used as substrates. However, the comments of Lawrence, Fryer \& Reiter ( $1967 a$ ) on bacterial lipases may apply equally to fungal lipases; that is since nothing is known of their natural substrates or their physiological role the choice of any substrate to detect these lipases must be arbitrary.

A study of the esterase profiles from various stages of the growth cycle of Bacillus cereus has revealed a changing pattern of enzymes (Baillie \& Norris, I963). A single esterase band was demonstrated in young cultures and the development of a second band was noted after I I h. growth.

As the physiological roles of fungal esterases have not been fully elucidated, a study

Vol. 63, No. I was issued I January $197 \mathrm{I}$ 
of these enzymes in three fungi was undertaken. This paper reports and discusses the role of esterases in the vegetative growth of Candida lipolytica, and in asexual sporulation in Aspergillus niger and an unidentified yeast-like fungus; their ability to hydrolyse glycerol tributyrin was also investigated.

\section{METHODS}

Organisms. (I) Candida lipolytica was isolated by Ross (1963); (2) an unidentified yeast-like fungus, referred to as isolate 48 , was isolated from a marine source (Lloyd, 1970) and produces arthrospores at the end of the growth cycle; and (3) Aspergillus niger van Tieghem (IMI 4I873). Stock cultures of (I) and (2) were maintained on malt extract-yeast extract-glucose-peptone (MYGP) slopes at $3^{\circ}$ and (3) on potatodextrose agar at $27^{\circ}$.

Media. For Candida lipolytica the glucose-mineral medium contained $\left(\mathrm{NH}_{4}\right)_{2} \mathrm{SO}_{4}$, 5.0 g.; $\mathrm{KH}_{2} \mathrm{PO}_{4}$, I.० g.; $\mathrm{MgSO}_{4} .7 \mathrm{H}_{2} \mathrm{O}, 0.5 \mathrm{~g}$.; $\mathrm{NaCl}$, 0.I g.; $\mathrm{CaCl}_{2} .2 \mathrm{H}_{2} \mathrm{O}$, 0.I g.; glucose, $\mathrm{I} 0.0 \mathrm{~g}$./ l. dist. $\mathrm{H}_{2} \mathrm{O}$. To examine the influence of the carbon source on esterase production, the above mineral medium was solidified with $2 \%(\mathrm{w} / \mathrm{v})$ agar (Oxoid no. 2) and either I \% (w/v) glucose or I \% (v/v) glycerol tributyrin (B.D.H.) was added.

For isolate 48, arthrospore production was induced in MYGP medium; this contained malt extract, 3.0 g.; yeast extract, $3.0 \mathrm{~g}$; glucose, 10.0 g.; peptone, 5.0 g./1. dist. $\mathrm{H}_{2} \mathrm{O}$. One ml. of a $50 \%$ aqueous solution of silicon MS antifoam emulsion RD (Hopkins \& Williams Ltd, Freshwater Road, Chadwell Heath, Essex) was added/ $500 \mathrm{ml}$. MYGP.

For Aspergillus niger, the basal-mineral medium used in the conidiation studies, referred to as ' $\mathrm{B}$ ' medium, contained $\mathrm{NH}_{4} \mathrm{NO}_{3}, 2 \cdot 5 \mathrm{~g}$.; $\mathrm{KH}_{2} \mathrm{PO}_{4}, \mathrm{I} \cdot 0 \mathrm{~g}$. $\mathrm{CaCl}_{2}, 46 \cdot 7 \mathrm{mg}$.; $\mathrm{MgSO}_{4} \cdot 7 \mathrm{H}_{2} \mathrm{O}$, I.I mg.; $\mathrm{MnCl}_{2} \cdot 4 \mathrm{H}_{2} \mathrm{O}, 3.5 \mathrm{mg}$.; $\mathrm{CuSO}_{4} .2 \mathrm{H}_{2} \mathrm{O}$, 0.234 mg.; $\mathrm{FeSO}_{4}$. ${ }_{7} \mathrm{H}_{2} \mathrm{O}, 6 \cdot 32 \mathrm{mg}$.; $\mathrm{ZnSO}_{4} \cdot 7 \mathrm{H}_{2} \mathrm{O}$, I. I mg./l. dist. $\mathrm{H}_{2} \mathrm{O}$. Conidiating cultures of $A$. niger were obtained on (i) ' $\mathrm{B}$ ' medium supplemented with (a) 20 mM-sodium $\alpha$-oxoglutarate, or $(b) 20 \mathrm{~mm}$-fumaric acid, or $(c) 20 \mathrm{~mm}$-glutamic acid, or $(d) 20 \mathrm{~mm}$-glycine, or $(e)$ 20 mm-leucine, and (ii) $\mathrm{NaNO}_{3}$ medium. The latter was identical to ' $\mathrm{B}$ ' medium except that $60 \mathrm{~mm}-\mathrm{NaNO}_{3}$ replaced $\mathrm{NH}_{4} \mathrm{NO}_{3}$. Sterile cultures were grown on unsupplemented 'B' medium (Galbraith \& Smith, I969a).

The media for Candida lipolytica and isolate 48 were adjusted to $\mathrm{pH} 5.5$ and for Aspergillus niger to $\mathrm{pH} 5^{\circ} \mathrm{O}$. All media were autoclaved for $\mathrm{I} 5 \mathrm{~min}$. at $12 \mathrm{I}^{\circ}$ except for glycerol tributyrin-mineral salts agar; in which case the glycerol tributyrin was sterilized separately by dry heat at $160^{\circ}$ for $2 \mathrm{~h}$. and was then emulsified, aseptically, with the autoclaved mineral salts-agar in a blender for $3 \mathrm{~min}$.

Turbidity measurements. All turbidity measurements were referred to water using the logarithmic scale on an EEL nephelometer with a neutral density filter.

Preparation of inocula. Liquid cultures of Candida lipolytica were grown in conical I l. flasks containing $500 \mathrm{ml}$. of medium. Surface cultures were grown in squat $500 \mathrm{ml}$. conical flasks containing $150 \mathrm{ml}$. of agar medium. Liquid cultures were inoculated with I $\mathrm{ml}$., and solid media with $2 \mathrm{ml}$., of a fungal suspension of turbidity 20 prepared from a $24 \mathrm{~h}$. MYGP slope culture grown at $25^{\circ}$.

Cultures of isolate 48 were grown in I l. conical flasks containing $500 \mathrm{ml}$. of medium; each flask was inoculated with $\mathrm{I} \mathrm{ml}$. of an arthrospore suspension of turbidity 20 prepared from a 7 day MYGP slope culture grown at $20^{\circ}$. 
Cultures of Aspergillus niger were grown in $250 \mathrm{ml}$. conical flasks containing $75 \mathrm{ml}$. of medium, and each flask was inoculated with approximately $8 \times 10^{6}$ conidia.

Incubation. Liquid cultures of the three organisms were incubated on an orbital shaker (Gallenkamp) at $150 \mathrm{rev} . / \mathrm{min}$. at the following temperatures: Candida lipolytica, $25^{\circ}$; isolate $48,20^{\circ}$; Aspergillus niger, $27^{\circ}$. Samples were harvested throughout the growth cycle. Agar cultures of $C$. lipolytica were harvested after 5 to 7 days growth at $25^{\circ}$.

Growth measurement. A turbidimetric method was used to estimate the amount of growth of Candida lipolytica and isolate 48 in liquid media because it was a simple method showing close linear correlation with dry wt determinations under the condition of growth employed for these studies. Isolate 48 and Aspergillus niger were examined microscopically for signs of sporulation.

Preparation of cell-free extracts. Candida lipolytica and isolate 48 were harvested by centrifugation, washed three times and resuspended in distilled water. The concentration of organisms in the suspensions was determined by diluting a sample of suspension to give a turbidity reading of 80 units and then adjusting the concentration of the suspension to equate to $\mathrm{I} 600$ units. The organisms were disintegrated for $5 \mathrm{~min}$. by an M.S.E. ultrasonicator (roo W output), the cups being immersed in solid $\mathrm{CO}_{2}+$ water. The extracts were centrifuged and the supernatant fluid stored at $-20^{\circ}$. Extracts of mycelial pellets of Aspergillus niger were prepared by sonication of $2 \mathrm{~g}$. of filter paper dried mycelium which had been ground for a short period in $5 \mathrm{ml}$. distilled water using a mortar and pestle. Samples of all extracts were freeze dried for $18 \mathrm{~h}$. and reconstituted for electrophoresis in a minimum quantity of $0.05 \mathrm{M}$-phosphate buffer, $\mathrm{pH} 8 \cdot 0$.

Electrophoresis. The cell-free extracts were analysed by electrophoresis in polyacrylamide gels by the method of Lund (1965) in a refrigerated room (5 to $\left.10^{\circ}\right)$ at constant voltage (13.75 V/cm.gel). The initial current was $20 \mathrm{~mA}$.

Detection of esterases. After electrophoresis the gels were sliced to four layers I. $\mathrm{mm}$. thick. The middle two slices were stained for esterases by a method adapted from that of Nachlas \& Seligman (1949). The slices were incubated for $2 \mathrm{~h}$. in a freshly prepared mixture of $0 \cdot \mathrm{I}$ M-tris-maleate buffer $(\mathrm{pH} 6 \cdot 4)$, IOO ml., $+\mathrm{I} \%(\mathrm{w} / \mathrm{v}) \alpha$-naphthyl acetate in $50 \%(\mathrm{v} / \mathrm{v})$ acetone in water, $2 \mathrm{ml}$. , + fast blue B salt (Gurr) ca. $0 \cdot 2$ g. Esterase activity was indicated by red bands and the position of the mid-point of each band was measured from the origin.

Quantitative esterase activity determination. Esterase activity was estimated by the method of Hobson \& Summers (1966) using: (I) intact Candida lipolytica and isolate 48 ; (2) the following preparations of Aspergillus niger grown on ' $\mathrm{B}$ ' medium + sodium $\alpha$-oxoglutarate: $(a)$ mycelial extracts, and $(b)$ mitochondrial suspensions prepared according to the method of Watson \& Smith (1967); and (3) cell-free growth medium of all three organisms. The buffered-substrate solution consisted of Io mg. of $\alpha$ naphthyl acetate dissolved in $2 \mathrm{ml}$. acetone and $98 \mathrm{ml}$. 0.1 M-tris-maleate buffer, pH 6.4. The reaction mixture consisted of $6 \mathrm{ml}$. buffered-substrate solution and $\mathrm{I} \mathrm{ml}$. of a suspension of washed organisms of turbidity 80 in distilled water, or $\mathrm{I}$ ml. of mycelial extract, or I ml. of cell-free growth medium. After $20 \mathrm{~min}$. incubation at 20 , 25 and $27^{\circ}$ for isolate $48, C$. lipolytica and $A$. niger respectively, I $\mathrm{ml}$. of fast blue B solution was added with $\mathrm{I} \mathrm{ml}$. of $40 \%$ (w/v) trichloracetic acid aqueous solution to facilitate extraction of the azo dye from the protein-containing solutions. The complex 
formed by the naphthol, released from the hydrolysed substrate, with the dye, was extracted in ethyl acetate. The extinction rates of the extracts were measured in a spectrophotometer at $540 \mathrm{~nm}$. The extinction readings were converted to $\mathrm{mg}$. of $\alpha$-naphthol liberated using a calibration curve obtained with $\alpha$-naphthol. The results are expressed as mg. $\alpha$-naphthol liberated/mg. dry wt organism for $C$. lipolytica and isolate 48 , as $\mathrm{mg}$. of $\alpha$-naphthol liberated $/ \mathrm{mg}$. protein for $A$. niger mycelial extracts and mitochondrial suspensions, and as $\mathrm{mg}$. $\alpha$-naphthol liberated $/ \mathrm{ml}$. of cell-free growth medium. The dry wt of cell material used was determined by drying $5 \mathrm{ml}$. of each suspension to a constant weight in an oven at $100^{\circ}$.

Assay of esterase bands for lipase activity. After electrophoresis, one slice was removed from the top of the gel and the esterases detected. The stained slice was washed with water, replaced in its original position on the top of the gel and the underlying esterase-containing gel excised. These unstained sections were pulverized in about I ml. of water and tested for lipolytic activity against glycerol tributyrin using the thin-layer agar diffusion method described by Lawrence, Fryer \& Reiter (1967b).

Manometric determinations. Gas exchanges by Candida lipolytica and isolate 48 were measured using $2 \mathrm{ml}$. of fresh culture. Oxygen uptake and carbon dioxide evolution were measured by standard Warburg techniques (Umbreit, Burris \& Stauffer, 1964).

Lipid determinations. Lipid contents were determined by the method of Pedersen (1962).

\section{RESULTS}

Candida lipolytica. Esterase profiles from organisms in early and mid-exponential and early stationary phases of growth in liquid glucose-mineral salts medium all contained the same number of esterase bands (Fig. I). In the profile of organisms from the early exponential growth phase all the bands stained with approximately the same intensity, whereas in the profiles of organisms from early stationary growth phase bands 44 and 66 showed the greatest size and staining intensity. The esterase activity of intact organisms increased throughout the growth cycle but was negligible in the growth medium over the same period (Fig. 3). The respiratory quotient decreased at the end of the growth cycle to a value indicating lipid utilization (Fig. 3).

No esterases were detected in cell-free extracts of Candida lipolytica grown for 5 to 7 days on the solid media when glucose was the sole carbon source; however, when glycerol tributyrin was substituted for glucose an esterase profile was demonstrated in which band 66 stained very heavily (Fig. I).

Isolate 48. A microscopic examination of this organism in MYGP broth showed that differentiation of vegetative cells into arthrospores occurred at approximately $72 \mathrm{~h}$. and was complete after $\mathrm{I} 45 \mathrm{~h}$. Electrophoretic analysis of esterase preparations from organisms at different stages of the growth cycle revealed a changing esterase profile (Fig. 2). The major esterases present after $24 \mathrm{~h}$. growth, bands $27,5 \mathrm{I}$ and 57 , became less prominent as growth proceeded. At the onset of sporulation ( $72 \mathrm{~h}$.) they were eclipsed by two heavily staining esterases, bands 59 and 67 . The increase in esterase activity between 48 and $96 \mathrm{~h}$. (Fig. 4) probably reflects the appearance of these two bands. Esterase activity was not measured beyond $96 \mathrm{~h}$. because the arthrospores were inert towards the ester substrate although extracts contained esterases. At $96 \mathrm{~h}$. approximately 20 to $30 \%$ of the cells were arthrospores and, therefore, the reported esterase activity is lower than would have been obtained with a suspension 
of only vegetative cells. No extracellular activity was noted. Another change which occurred at the onset of sporulation $(72 \mathrm{~h}$.) was a sharp increase in lipid content followed by a decrease during sporulation. A fall in the respiratory quotient from approximately $\mathrm{I} \cdot \mathrm{O}$ at $72 \mathrm{~h}$. to 0.748 at $96 \mathrm{~h}$. was consistent with decrease of the lipid content of the organism.

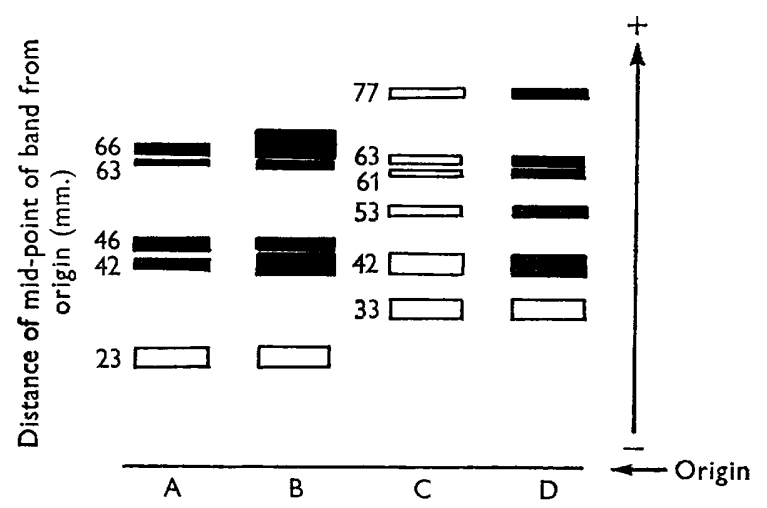

Fig. I. Diagram of esterase profiles obtained by electrophoresis on polyacrylamide gel of extracts of Candida lipolytica and Aspergillus niger. (A) C. lipolytica from early exponential phase of growth in liquid glucose-mineral salts medium. (B) C. lipolytica from late exponential/early stationary phase of growth both in liquid glucose-mineral salts medium and on solid glycerol tributyrin-mineral salts medium. (C) A. niger from $48 \mathrm{~h}$. growth, and (D) from $72 \mathrm{~h}$. and $96 \mathrm{~h}$. growth in liquid medium M+ + -oxoglutarate. NB. No esterases were detected in $A$. niger after 24 h. growth in liquid medium M+ $+\alpha$-oxoglutarate. $\square$, Weak esterase activity; $\boldsymbol{\sim}$, intense esterase activity.

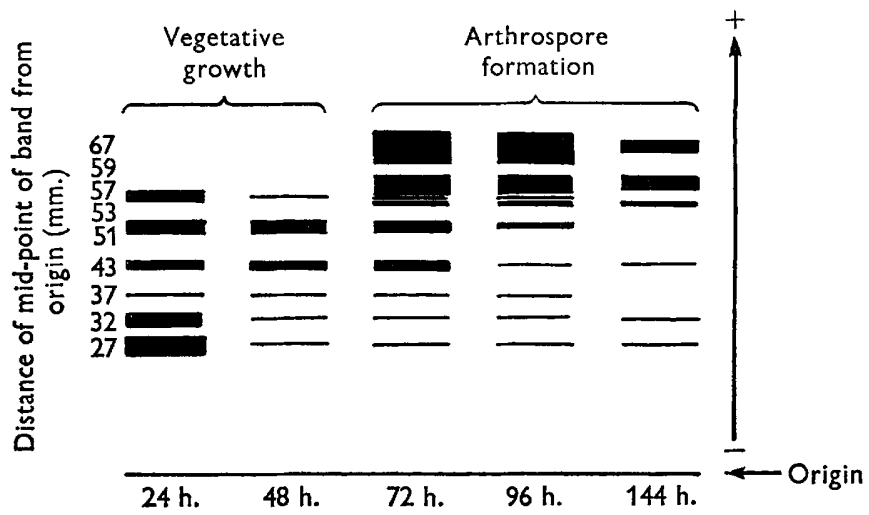

Fig. 2. Diagram of esterase profiles obtained by electrophoresis of extracts of isolate 48 , on polyacrylamide gels, from different stages of the growth cycle on MYGP medium.

Aspergillus niger. Esterases were always detected during conidiation but never in vegetative growth in conidiating media nor in sterile cultures. Esterase profiles obtained from different stages of growth of $A$. niger in ' $\mathrm{B}$ ' medium $+\alpha$-oxoglutarate show that a weakly staining multimolecular profile appeared at the onset of conidiophore formation and an intensely staining profile appeared during conidia formation (Fig. I). This change in the staining intensity is reflected in the increase in esterase activity (Fig. 5). Esterase activity was absent both from mitochondrial suspensions and from 


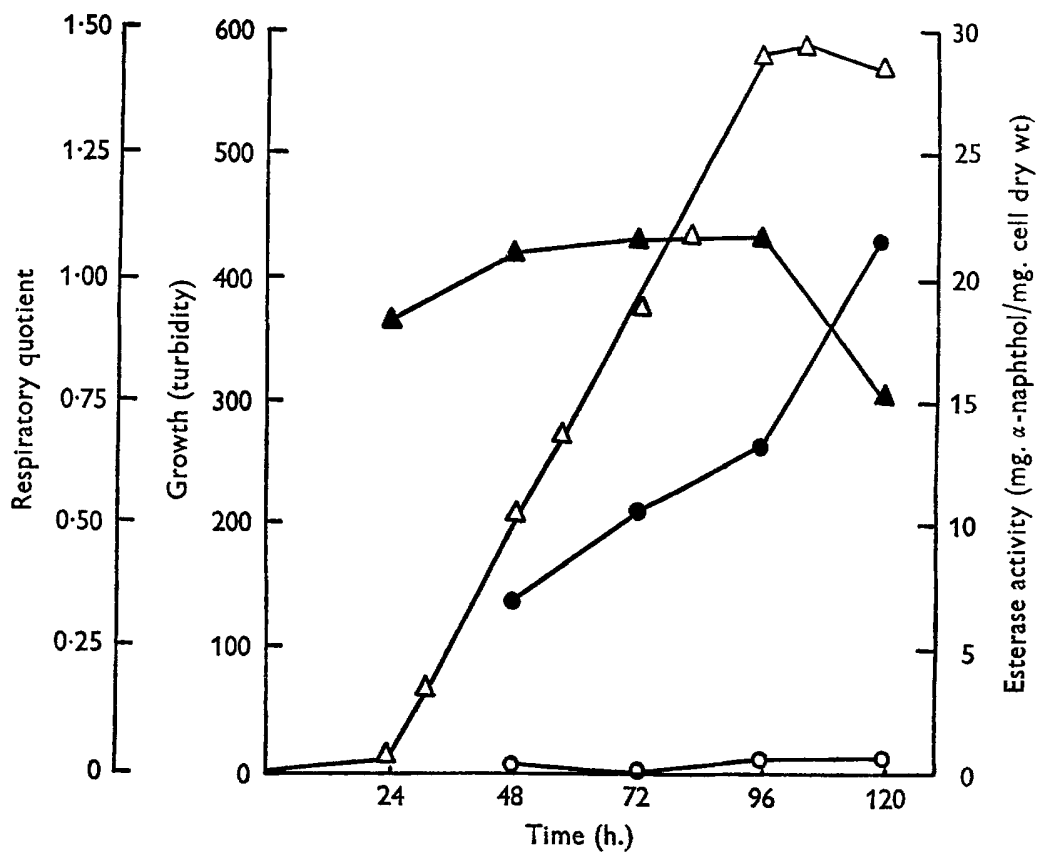

Fig. 3. Comparison of esterase activity, respiratory quotient, and growth of Candida lipolytica grown in liquid glucose-mineral salts medium. $\triangle-\triangle$, Growth measured as turbidity units in EEL nephelometer; $\Delta-\Lambda$, respiratory quotient; $\bullet-\bullet$, esterase activity of yeast; $\mathrm{O}-\mathrm{O}$, esterase activity of medium freed of yeast.

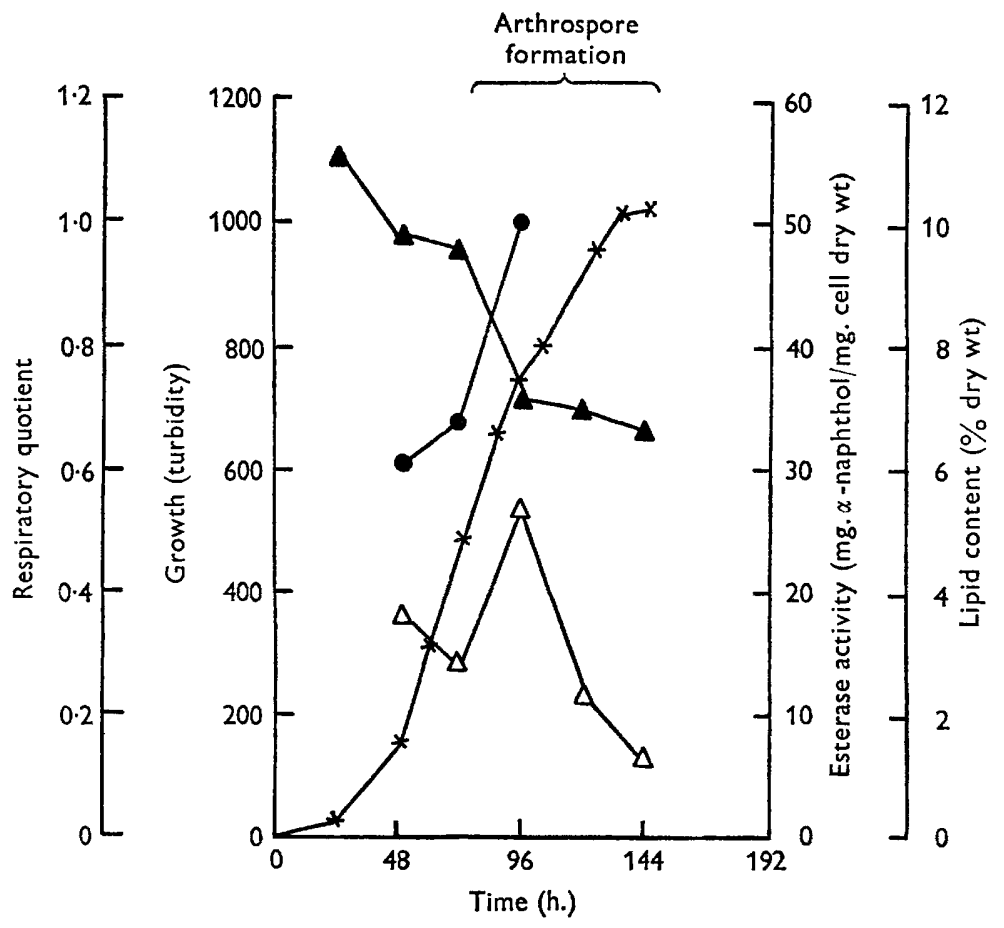

Fig. 4. Comparison of esterase activity, respiratory quotient, growth and lipid content of isolate 48 grown in MYGP medium. $\times-\times$, Growth as measured by turbidity units; $\Delta-\triangle$, respiratory quotient; $-\longrightarrow$, esterase activity of organism; $\triangle-\triangle$, lipid content of organism. 
the medium throughout the growth period. Esterase profiles from conidiating cultures in the other media were similar to those shown in Fig. I; the two major bands in all profiles were 42 and 53 . All esterases of the three fungi hydrolysed glycerol tributyrin.

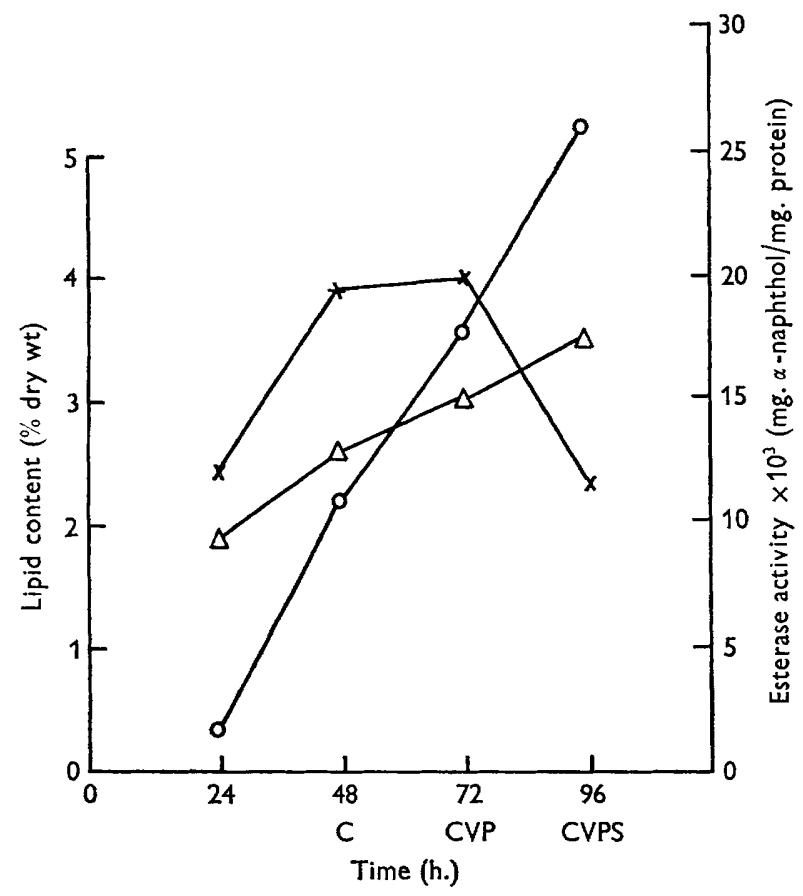

Fig. 5. Comparison of esterase activity and lipid content of Aspergillus niger in medium M or medium $\mathrm{M}+\alpha$-oxoglutarate. $\mathrm{C}=$ Conidiophores; $\mathrm{V}=$ vesicles; $\mathrm{P}=$ phiallides; $\mathrm{S}=$ spores. $\mathrm{O}-\mathrm{O}$, Esterase activity of organism grown in medium $\mathbf{M}+\alpha$-oxoglutarate (no esterase activity from organism grown on medium $M$ ); $\times-\times$, lipid content of organism grown in medium $\mathrm{M}+\alpha$-oxoglutarate; $\Delta-\Delta$, lipid content of organism grown in medium $M$.

\section{DISCUSSION}

Cell-free extracts from Candida lipolytica grown in liquid medium and examined by electrophoresis contained five distinct esterase bands. Esterase profiles of the organism from different stages of the growth cycle revealed the same five enzymes. In the early stationary phase profile the relative increase in size and intensity of bands 42 and 66 probably reflects the increase in esterase activity which occurred throughout the growth cycle. The failure to demonstrate esterase profiles in extract of $C$. lipolytica grown on solid glucose medium is unexplained.

Three observations suggest that the esterases of Candida lipolytica may be involved in the metabolism of intracellular and extracellularly added lipids. The first is that all the excised esterases of $C$. lipolytica hydrolysed glycerol tributyrin and can be classified as lipases according to the arbitrary definition of Lawrence (1967a) that lipases attack triglycerides. The second is that the natural substrate of the esterases may be lipid as they are induced when C. lipolytica is grown on solid glycerol tributyrin medium. The third is the finding that the very small increase in extracellular esterase activity did not parallel the large increase in intracellular activity. This indicates that 
some, if not all, of the esterases are situated on or in the organism. Support for this is provided by Peters \& Nelson (1948), who were unable to detect any extracellular esterase activity in $C$. lipolytica. The validity of the suggestion for the physiological role of the esterases in C. lipolytica is supported by the work of Nyns, Chiang \& Wiaux (I968). Using similar growth conditions and liquid medium as in this paper, they showed that $C$. lipolytica contained twice as much lipid in the exponential phase as in the stationary phase of growth. The decrease in lipid was attributed to its consumption in the late phases of growth.

Esterase profiles of isolate 48 indicate that some of these enzymes may have an important function at a particular phase in its life cycle because a significant change in the profile occurred at the onset of arthrospore formation with the appearance of bands 55, 59 and 67. The appearance of these esterase bands coincided with the rise in esterase activity. The ability of the excised esterases to hydrolyse tributyrin implies that they may be involved in intracellular lipid utilization, particularly during arthrospore production. The extent of the contribution of intracellular lipid to the metabolism of sporulation can be judged from the large decrease in lipid content which occurs during the process. The rapid accumulation of lipid which occurs at the end of vegetative growth may indicate the point of cessation of the phase of balanced growth due to the exhaustion of some particular nutrient component such as $\mathrm{N}$ or $\mathrm{P}$, which, according to Bu'Lock \& Powell (1965), may lead to secondary metabolism, an example of which is fat synthesis in yeasts in the absence of assimilable N. Events which terminate balanced growth in fungi, e.g. substrate limitation such as the limitation of assimilable nitrogen (Morton, I967), also act as morphogenetic stimuli. Thus by extrapolation of the original observation of the change in esterase profile and quantitative esterase activity the following sequence of events leading to differentiation can be visualized. The termination of balanced growth leads to an accumulation of intracellular lipid which is rapidly followed by the induction of differentiation for which process the lipid provides an endogenous carbon and energy source. Although there is no direct evidence that esterase band 27 , which is very prominent in the $24 \mathrm{~h}$. profile, is involved in germination of the arthrospores, this possibility cannot be excluded as lipid metabolism has been shown to be predominant in the germination of Penicillium roqueforti conidia (Lawrence, $1967 b$ ) and in stem rust uredospores (Farkas \& Ledingham, 1959).

In Aspergillus niger, lipolytic esterases are always present during conidiation irrespective of the mode of induction of the latter. Furthermore, esterases have neither been detected in vegetative mycelium from these cultures nor throughout the growth of sterile cultures. From the electrophoresis studies, the subjective impression is that the greatest esterase activity occurred at the time of conidia production and not during conidiophore development. This impression was confirmed by measurements of esterase activity on $A$. niger grown in 'B' medium $+\alpha$-oxoglutarate. In this particular case the change in the level of lipolytic esterase activity and the intracellular lipid consumption during differentiation appear to be interrelated. If this is so, the implication is that the lipid functions as a source of carbon and energy during conidiation. Such a function for lipid reserves occurs in other organisms, e.g. during the differentiation of amoebae to cysts, the lipid of the vegetative organism is converted via the glyoxylate cycle to cyst-wall cellulose (Tomlinson, 1967). An active glyoxylate cycle has also been shown to occur during differentiation in $A$. niger (Galbraith \& Smith, $\mathrm{I} 969 \mathrm{~b})$. This cycle may be metabolically co-ordinated with lipid utilization and act 
as an anaplerotic pathway or, as suggested by Galbraith \& Smith, may provide a source of glyoxylate which could be transaminated to glycine which may act as a purine precursor in the nucleic acid synthesis necessary for transcription of genes active in differentiation.

In postulating a probable correlation between esterase production and conidiation in Aspergillus niger, it is necessary to consider the suggestion by Mandelstam (1969), that before any correlation can be regarded as being established it is necessary to show that an event is invariably correlated with a particular morphological stage. The present study has shown that esterase production is always associated with conidiation irrespective of the type of sporulation medium, and initial studies by Craig, Lloyd \& Smith (unpublished material) have shown that by using a replacement medium to induce conidiation (J. G. Anderson \& J. E. Smith, personal communication), esterases are produced during conidiation irrespective of the previous growth medium. Although a correlation does not establish a causal relationship, such a relationship is implicit in the suggestion that differentiation in isolate 48 and $A$. niger is assisted by or even dependent upon the utilization of stored lipid which can provide an endogenous carbon and energy source. This interpretation is consistent with the hypothesis of Wright (1967, 1970), that the characteristic common to most, if not all, forms of morphogenesis is that they are essentially endogenous, self-sufficient systems which have the ability to use endogenous reserves both extensively and efficiently. Wright (1970) also considers that each differentiating system starts with a fixed amount of endogenous reserve material which is used in an orderly and sequential manner and that the changes in endogenous metabolism alter the composition of small molecules or populations of inducers essential for gene activation.

Experiments in progress, using different techniques to obtain cell-free extracts, suggest that the multimolecularity of the esterase profile in Aspergillus niger is not an artefact. The importance of this enzyme heterogeneity may lie in its ability to control lipid metabolism during differentiation. Each esterase could, for example, be subject to regulation by a different end-product or each may be associated with a different lipid pool, each pool being used at one unique stage in differentiation; these control mechanisms may even be the pacemakers of differentiation itself.

\section{REFERENCES}

Arnason, A. \& Pantelouris, E. M. (1966). Serum esterases of Apodemus sylvaticus and Mus musculus. Comparative Biochemistry and Physiology 19, 53.

BaILliE, A. \& Norris, J. R. (1963). Studies of enzyme changes during sporulation in Bacillus cereus, using starch gel electrophoresis. Journal of Applied Bacteriology 26, I02.

Bu'LOCK, J. D. \& Powell, A. T. (1965). Secondary metabolism: an explanation in terms of induced enzyme mechanics. Experientia 2I, 55.

Farkas, G. L. \& Ledingham, G. A. (I959). The relation of self-inhibition of germination to the oxidative metabolism of stem rust uredospores. Canadian Journal of Microbiology 5, I4I.

Galbraith, J. C. \& SMITH, J. E. (I969a). Sporulation of Aspergillus niger in submerged liquid culture. Journal of General Microbiology 59, 31.

Galbraith, J. C. \& Smith, J. E. (1969b). Changes in activity of certain enzymes of the tricarboxylic acid cycle and the glyoxylate cycle during the initiation of conidiation of Aspergillus niger. Canadian Journal of Microbiology 15 , 1207.

Hobson, P. N. \& SUMmERs, R. (1966). Effect of growth rate on the lipase activity of a rumen bacterium. Nature, London 209, 736. 
InTERNATIONAL UNION OF Biochemistry (196I). Report of the Commission on Enzymes. Oxford: Pergamon Press.

LAWRENCE, R. C. (1967a). Microbial lipases and related esterases. Dairy Science Abstracts 29, I.

LAWrence, R. C. (1967 b). The metabolism of triglycerides by spores of Penicillium roqueforti. Journal of General Microbiology 46, 65.

LAWRENCE, R. C., FRYER, T. F. \& ReITER, B. (1967a). The production and characterization of lipases of a Micrococcus and a Pseudomonad. Journal of General Microbiology 48, $40 \mathrm{I}$.

LaWrence, R. C., Fryer, T. F. \& Reiter, B. (1967b). A rapid method for the quantitative estimation of microbial lipases. Nature, London 213, I 264.

LLOYD, G. I. (1970). The Identification, Physiology and Biochemistry of Some Marine-occurring Yeasts. $\mathrm{Ph}$.D. Thesis, University of Strathclyde, Glasgow.

LUND, B. M. (I965). A comparison by the use of gel electrophoresis of soluble protein components and esterase enzymes of some group D streptococci. Journal of General Microbiology 40, 413.

Mandelstam, J. (1969). In Microbial Growth, 19th Symposium for the Society of General Microbiology. Edited by Pauline M. Meadow \& S. J. Pirt. Cambridge University Press.

Morton, A. G. (1967). Morphogenesis in fungi. Science Progress, Oxford 55, 597.

Nachlas, M. M. \& Seligman, A. M. (1949). The histochemical demonstration of esterase. Journal of the National Cancer Institute 9, 415.

NoRRIs, J. R. (1964). The classification of Bacillus thuringiensis. Journal of Applied Bacteriology $27,439$.

Nyns, E. J., Chiang, N. \& Wiaux, A. L. (1968). Comparative lipid content of Candida lipolytica grown on glucose and on $n$-hexadecane. Antonie van Leeuwenhoek 34, 197.

Peters, I. I. \& Nelson, F. E. (1948). Factors influencing the production of lipase by Mycotorula lipolytica. Journal of Bacteriology 55, 581.

RoBinson, K. (1966). An examination of Corynebacterium spp. by gel electrophoresis. Journal of Applied Bacteriology 29, 179.

Ross, S. S. (1963). A Study of Yeasts of Marine Origin. Ph.D. Thesis, University of Glasgow.

Tombinson, G. (1967). The glyoxylate pathway in Acanthamoeba sp. Journal of Protozoology 14, II4.

Umbreit, W. W., Burris, R. H. \& Stauffer, U. F. (1964). Manometric Techniques, 4th edn. Minneapolis (Minnesota): Burgess Publ. Co.

WATSON, K. \& SMITH, J. E. (1967). Oxidative phosphorylation and respiratory control in mitochondria from Aspergillus niger. Biochemical Journal ro4, 332.

Wright, B. E. (1967). On the evolution of differentiation. Archiv für Mikrobiologie 59, 335.

WRIGHT, B. E. (1970). On the evolution of substrate control in differentiation. Evolutionary Biology 4 (in Press). 